\title{
KONTRIBUSI KELENTUKAN PERGELANGAN TANGAN TERHADAP KETEPATAN HASIL PUKULAN SERVIS BACKHAND BACKSPIN PADA TENIS MEJA
}

\author{
Melya Nur Herliana \\ Universitas Siliwangi \\ Email : melya.nh22@unsil.ac.id
}

\begin{abstract}
Abstrak
Tujuan dari Penelitian ini adalah untuk memperoleh informasi tentang kontribusi kelentukan pergelangan tangan terhadap ketepatan hasil pukulan servis backhand backspin pada tenis meja di ekstrakurikuler tenis meja SMK Negeri 2 Kota Tasikmalaya. Metode penelitian yang digunakan adalah metode deskriptif dimana dalam penelitian ini menggambarkan secara sistematik dan akurat mengenai fakta dan karakterisktik pada populasi, sampel dalam penelitian ini berjumlah 20 orang. Instrumen tes atau alat ukur yang digunakan dalam penelitian ini adalah mengukur kelentukan pergelangan tangan (Gonometri) dan mengukur kemampuan ketepatan servis backhand backspin. Berdasarkan hasil penelitian, pengolahan data, analisis data, dan pengujian hipotesis, maka dapat ditemukan terdapat kontribusi yang cukup besar dari kelentukan pergelangan tangan terhadap ketepatan hasil pukulan servis backhand backspin pada tenis meja di ekstrakurikuler tenis meja SMK Negeri 2 Tasikmalaya dengan prsentasi nilai sebagai berikut : kelentukan pergelangan tangan terhadap ketepatan servis backhand backspin $=0,44^{2} x 100 \%=19,4 \%$ Lainnya $=100 \%-19,4 \%=80,6 \%$. Dari hasil pembahasan dapat disimpulkan bahwa kelentukan pergelangan tangan terbukti memberikan kontribusi terhadap ketepatan hasil pukulan servis backhand backspin pada permainan tenis meja, namun ada ha-hal lain yang bisa menunjang terhadap hasil pukulan servis backhand backspin seperti kekuatan, koordinasi mata tangan, tingkat konsentrasi pelaku servis (mental), pengaruh bet dan karet yang mana perlu diteliti lebih lanjut.
\end{abstract}

Kata Kunci : backhand, backspin, kelentukan, servis.

\begin{abstract}
The purpose of this study was to obtain information about the contribution of wrist flexion to the accuracy of the results of backhand backspin service punches on table tennis in table tennis extracurricular at SMK Negeri 2 Kota Tasikmalaya. The research method used is descriptive method in which this study systematically and accurately describes the facts and characteristics of the population, the sample in this study amounted to 20 people. Test instruments or measuring instruments used in this study are measuring wrist flexion (gonometry) and measuring the ability of the backhand backspin service accuracy. Based on the results of research, data processing, data analysis, and hypothesis testing, it can be found that there is a significant contribution of wrist flexion to the accuracy of the results of backhand backspin service punches on table tennis with the following value values: wrist flexion to the precision of backspin backhand service $=$ $0.44^{2} \times 100 \%=19.4 \%$ Other $=100 \%-19.4 \%=80.6 \%$. From the results of the discussion it can be concluded that wrist flexion is proven to contribute to the accuracy of the results of backhand backspin service punches in table tennis, but there are other things that can support the results of backhand backspin service punches such as strength, hand eye coordination, concentration level of service players (mental), the effect of bet and rubber which needs to be further investigated.
\end{abstract}


Keywords : backhand, backspin, flexibility, service.

\section{PENDAHULUAN}

Tenis meja merupakan olahraga yang dapat dilakukan oleh siapa saja dari mulai orang tua, remaja, anak anakbaik laki - laki ataupun perempuan. Tenis meja olahraga yang memerlukan sarana prasarana yang tidak terlalu mahal dan memakan tempat yang luas, hanya dengan sebuah meja, bet dan bola maka olahraga tenis meja dapat dilakukan. Hal ini yang membuat olahraga tenis meja begitu pesat perkembangannya dilihat dari banyaknya klub di daerah - daerah yang bermunculan dan pertandingan atau kejuaraan yang sering dilaksanakan setiap tahunnya. Tenis meja adalah olahraga yang menggunakan raket yang paling terkenal di dunia dan jumlah partisipasinya menempati urutan kedua (Hodges, 1996), Table tennis is a widespread sport and this could have positive effects on the further development of the sport (Fuchs et al., 2018) Tenis meja adalah merupakan suatu cabang olahraga yang unik dan bersifat rekreatif, oleh karena itu cabang olahraga ini sangat digemari oleh anakanak, mereka yang berusia muda maupun mereka yang sudah lanjut usia (Indrawan \& Herliana, 2008), Tenis meja adalah olahraga semua umur dan bisa dianggap sebagai rekreasi maupun sebagai pemacu prestasi. Keduanya bisa dinikmati sekaligus, tetapi untuk memperlakukannya sebagai olahraga, perlu dipahami dulu berbagai teknik dan gaya permainan yang ada (Simpson, 1981),. tenis meja adalah suatu permainan yang menggunakan meja sebagai lapangan yang dibatasi oleh jaring (net) yang menggunakan bola kecil yang terbuat dari celluloid dan permainannya menggunakan pemukul atau yang disebut dengan bet (Depdiknas, dalam (Tomoliyus, n.d.). Jadi tenis meja adalah permainan bola kecil yang mana memainkan permainan tenis meja tidak perlu memakan ruangan yang terlalu besar, masyarakat hanya menyediakan meja dan bet untuk melakukan olahraga tenis meja.

Teknik dasar dalam permainan tenis meja diantaranya adalah teknik pegangan bet, teknik stance, teknik pukulan dan teknik servis. Untuk mengawali permainan tenis meja dilakukan dengan teknik servis. Dalam olahraga permainan tenis meja servis bisa dijadikan awal permulaan permainan berlangsung ataupun sebagai serangan awal untuk mendapatkan poin (Indrawan \& Herliana, 2008). Servis adalah salah satu teknik yang paling penting. Penguasaan servis harus baik karena servis adalah kesempatan pertama untuk menguasai permainan dan memegang inisiatif. Servis adalah suatu gerakan yang membutuhkan kecepatan. Pergelangan tangan adalah bagian dari tangan yang sanggup bergerak paling cepat. Dengan pergerakan pergelangan tangan, pemain dapat merubah sudut bet waktu bet menyentuh bola. Jenis servis dalam olahraga permainan tenis meja sangatlah banyak dan bervariatif, karena servis dalam olahraga permainan ini bisa menjadi alat mematikan diawal permainan yang dapat menghasilkan poin. Jadi banyak pemain tenis meja yang berlomba-lomba membuat variasi servis yang unik. Bahkan servis tiap pemain dalam permainan tenis meja itu berbeda-beda dan adapun servis yang menjadikan ciri khas seorang pemain. Servis yang sulit bisa menjadikan lawan tidak dapat mengembalikannya dengan baik bahkan bisa langsung menghasilkan sebuah poin.

Salah satu servis yang dapat mematikan lawan atau memancing lawan agar server dapat menyerang adalah servis backhand backspin. Jika servis tersebut dapat ditempatkan ditempat yang tepat maka lawan tidak 
memiliki banyak pilihan untuk mengembalikan servis yang diberikan oleh server. Jika servis tersebut langsung diserang akan berat bagi penerima servis dan resiko yang dihasilkan dari pukulan pengembalian bola dari penerima servis kepada server tidak dapat melewati net atau dengan kata lain bola tersebut akan menyangkut di net. Dan pilihan terakhir adalah hanya menyimpan bola tersebut dengan teknik chop dan resiko yang didapat adalah bola tersebut menjadi umpan baik untuk server melakukan serangan yang mematikan.

Selain itu hal terpenting dalam servis baik forehand topspin, forehand backspin, backhand topspin maupun backhand backspin adalah penempatan bola yang tepat. Jika bola dapat ditempatkan ditempat yang tepat dan pemain dapat mengetahui kelemahan lawan, servis dapat dijadikan senjata untuk menghasilkan poin dengan mengelabui lawan menggunakan penempatan bola yang tepat. Servis adalah tanda dimulainya permainan. Dalam tenis meja servis dapat dilakukan dalam dua teknik, yaitu forehand (servis forehand) dan backhand (servis backhand).

Jadi, yang dimaksud servis backhand backspin adalah servis yang dilakukan dengan menggunakan bagian belakang kepala bet dan arah putarannya/jenis putarannya ke belakang atau ke bawah (backspin) yang berarti servis tersebut berkarakter tajam atau padat yang akan sulit bagi penerima servis untuk menyerang. Untuk dapat melakukan servis yang baik dan benar dibutuhkan beberapa komponen kondisi fisik. Melihat dari karakter teknik servis dapat dilihat komponen kondisi fisik yang menunjang terhadap keberhasilan teknik servis yaitu kelentukan pergelangan tangan, kelentukan panggul, power otot lengan, koordinasi antara tangan, mata dan kaki dan faktor penunjang lainnya yang sangat penting adalah konsentrasi yang baik (mental). Dari komponen kondisi fisik yang menunjang tersebut belum diketahui mana yang mempunyai persentasi yang besar terhadap keberhasilan teknik servis. Artikel ini akan mengungkap kontribusi pergelangan tangan terhadap keberhasilan servis backhand backspin.

Pentingnya keletukan untuk bisa menghasilkan servis karena kelentukan merupakan komponen kebugaran jasmani yang harus dimiliki atlet dalam cabang olahraga apapun. (Harsono, 1988) kelentukan adalah Kemampuan untuk bergerak dalam ruang gerak sendi. Kelentukan pergelangan tangan adalah kemampuan ruang gerak sendi di bagian pergelangan tangan. Dalam permainan tenis meja kelentukan pergelangan tangan sangat dibutuhkan oleh pemain khusunya dalam teknik servis. Karena kelentukan pergelangan tangan berfungsi untuk mengatur arah bola sesuai dengan keinginan diri sendiri. Menurut Nicky Jarvis (Indrawan \& Herliana, 2008) menyebutkan bahwa "Gerakan sikut dan pergelangan tangan dalam melakukan servis merupakan peranan penting". Jadi kelentukan sangat penting dalam melakukan teknik servis karena dengan kelentukan yang baik akan mendapatkan servis yang baik dan mampu mematikan lawan.

\section{BAHAN DAN METODOLOGI}

Penelitian ini dilakukan di ekstrakulikuler siswa SMK 2 Tasikmalaya dengan jumlah sampel 20 orang. Metode penelitian ini menggunakan metode deskriptif, Badri, Sutrisno (2012) berpendapat bahwa metode deskriptif merupakan metode penelitian yang melakukan analisis hanya sampai taraf deskripsi, yaitu menganalisis dan menyajikan data secara sistematik, sehingga dapat lebih mudah untuk dipahami dan disimpulkan. Penelitian deskriptif bertujuan menggambarkan secara sistematik dan akurat fakta dan karakteristik mengenai 
populasi atau mengenai bidang tertentu. Analisis yang sering digunakan adalah: analisis presentase dan analisis kecenderungan. Kesimpulan yang dihasilkan tidak bersifat umum. Jenis penelitian deskriptif yang dikenal adalah penelitian survei.

Data penelitian ini didapatkan dalam mengukur pergelangan tangan dan mengukur tes servis. Arikunto (2014) menjelaskan bahwa instrumen penelitian adalah "Alat atau fasilitas yang digunakan oleh peneliti dalam mengumpulkan data agar pekerjaannya lebih mudah dan hasil lebih baik, dalam arti lebih cermat, lengkap dan sistematis sehingga lebih mudah diolah". Setiap objek penelitian mempunyai ciri khas yang mengharuskan peneliti merancang instrumen yang akan digunakan. Alat ukur untuk mengukur kelentukan pergelangan tangan adalah Gonometri dengan reliabilitas tes sebesar 0,51 dan validitas tes sebesar 0,97. (Supriatna, Tono, 2002). Pelaksanaan:

1) Tangan diletakkan lurus sejajar dengan titik $0^{0}$ dan pergelangan tangan tepat berada pada titik pusat. Posisi tangan diletakan sesuai dengan tujuan dan arah pengukuran.

2) Tangan dibengkokan sejauh mungkin sesuai dengan tujuan dan arah pengukuran dan pergelangan tangan tetap berada tepat pada titik pusat.

3) Mencatat angka yang ditunjukan, yang merupakan skornya, atau luas gerak sendi pergelangan tangan pada salah satu arah gerak.

Tes servis backhand backspin menurut Tomoliyus (2017) sebagai berikut:

Bertujuan untuk mengukur kemampuan ketepatan servis backhand backspin. Dengan validitas 0.90 dan reliabilitas untuk pemula 0.80 dan untuk yunior 0.82 Alat yang dibutuhkan untuk melaksanakan tes tersebut yaitu bola tenis meja, bat, tali, skor shet. Tanda meja untuk tiga sasaran yaitu pertama luas 152,5 x $35 \mathrm{~cm}$, kedua luasnya 152,5 x $35 \mathrm{~cm}$, dan ketiga luasnya 152,5 x 67 $\mathrm{cm}$. Jarak tali net $20 \mathrm{~cm}$.

a. Petunjuk tes:

1) Subyek disuruh melakukan pemanasan dan latihan (practice) secukupnya.

2) Subyek melakukan servis backspin ke arah sasaran, bolanya lewat dibawah tali.

3) Subyek melakukan servis 10 kali kearah sasaran sebelah kanan dan 10 kali ke arah sasaran sebelah kiri secara bergantian.

b. Petunjuk penyekoran:

1) Penyekoran dilakukan 2 orang, 1 orang pencatat dan 1 orang mengamati bola masuk ke sasaran.

2) Pencatat mengamati bola hasil servis tes yang lewat dibawah tali dan masuk sasaran.

3) Skor = menjumlahkan nilai sasaran dari servis 20 kali.

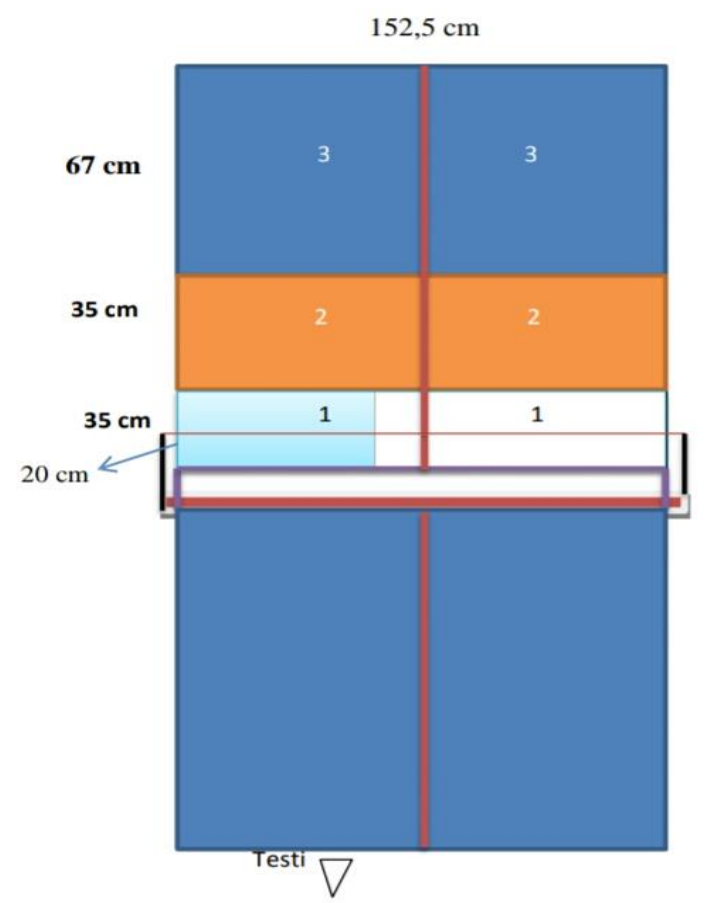

Gambar 1 Denah Lapangan Tes Sumber: Tomoliyus (2017) 
Dari tes instrumen servis backhand backspin di atas, dapat disimpulkan kriteria dari masing-masing kolom yang telah ada menurut expert dalam permainan tenis meja, bahwa skor terbesar adalah daerah tersulit lawan untuk mengembalikan bola, dan daerah skor terkecil adalah daerah termudah lawan untuk mengembalikan bola. Kriteria tes servis backhand backspin di atas adalah, sebagai berikut:

a) Nilai satu : Mudah. Apabila bola jatuh di daerah skor nomor satu, maka bola akan memantul pelan sehingga mudah untuk dikembalikan.

b) Nilai dua : Cukup sulit. Apabila bola jatuh di daerah skor nomor dua, maka cukup sulit bagi lawan untuk mengembalikan bola. Karena bola yang jatuh di daerah tersebut bersifat tanggung.

c) Nilai tiga : Sulit. Apabila bola jatuh di daerah skor nomor tiga, maka bola akan melaju dengan keras, cepat dan sangat tajam. Jadi, lawan akan sangat sulit untuk mengembalikan bola tersebut.

\section{HASIL DAN PEMBAHASAN}

\section{A. Deskripsi Data}

Sesuai dengan permasalahan yang penulis bahas dalam penelitian ini, berikut adalah data yang diperoleh dari serangkaian pengukuran yaitu, pengukuran kelentukan pergelangan tangan (X) dan ketepatan servis backhand backspin dalam tenis meja (Y).

Tabel 1. Data Hasil Penelitian

Kelent

No. Nama Perg.

Tanga

$\mathrm{n}$

\begin{tabular}{clc}
\hline 1 & UPIK TAUPEK & 90 \\
\hline 2 & M SAEPUL ANWAR & 100 \\
\hline 3 & IZAL MUHAMAD & 90 \\
\hline 4 & JAMALUDIN & 80 \\
\hline
\end{tabular}

\begin{tabular}{clc}
5 & DIKA PERMANA & 100 \\
\hline 6 & M ZIDAN & 80 \\
\hline 7 & MAULANA & 90 \\
\hline 8 & RIO SURYA & 80 \\
\hline 9 & DIMAS & 90 \\
\hline 10 & AGUNG & 100 \\
\hline 11 & MUNEBURRAHMAN & 90 \\
\hline 12 & YOGA & 100 \\
\hline 13 & GILANG MAULANA & 100 \\
\hline 14 & DILAR YUANDA & 90 \\
\hline 15 & M FAHMI & 80 \\
\hline 16 & M SUGIH & 100 \\
\hline 17 & DONNY & 90 \\
\hline 18 & M ALFIN & 90 \\
\hline 19 & SEPTIAN H & 100 \\
\hline 20 & RIZKY SABANDARI & 100 \\
\hline
\end{tabular}

Berdasarkan tabel di atas dapat dilihat bahwa untuk instrumen penelitian pertama, yaitu kelentukan pergelangan tangan, yang diperoleh dengan menggunakan teknik dengan alat ukur busur derajat. Responden yang memiliki kelentukan pergelangan tangan terbesar adalah responden nomor ke 2, 5, 10, 12, 13, 16, 19, dan 20 dengan kelentukan pergelangan tangan sebesar $100^{\circ}$, sedangkan responden dengan kelentukan pergelangan tangan terkecil adalah responden ke 4, 6, 8, dan 15 dengan kelentukan pergelangan tangan sebesar $80^{\circ}$.

B. Pengujian Persyaratan Analisis

Uji normalitas merupakan salah satu pengujian persyaratan untuk suatu analisis. Pengujian ini dilakukan untuk mengetahui apakah data yang digunakan terdistribusi normal. Jika data terdistribusi normal, maka akan digunakan pengujian menggunakan statistika parametrik dengan menggunakan korelasi sederhana. Namun, jika data diketahui tidak berdistribusi normal, maka akan digunakan pengujian menggunakan 
statistika nonparametrik dengan menggunakan korelasi Rank Spearman. Suatu data dikatakan normal jika nilai $\mathrm{L}_{\text {hitung }}<\mathrm{L}_{\text {tabel. }}$ Maka, dengan menggunakan program Microsoft Excel. Tabel 2. Hasil Pengujian Normalitas

\begin{tabular}{lccl}
\hline \multicolumn{1}{c}{ Variabel } & $\mathrm{L}_{\text {hitung }}$ & $\mathrm{L}_{\text {tabel }}$ & Status \\
\hline $\begin{array}{l}\text { Kelentukan } \\
\text { Pergelangan }\end{array}$ & 0,203 & 0,190 & $\begin{array}{l}\text { Tidak } \\
\text { Tangan }\end{array}$ \\
& & & \\
\hline
\end{tabular}

Berdasarkan tabel di atas, dapat dilihat bahwa untuk variabel kelentukan pergelangan tangan tidak berdistribusi normal karena nilai $\mathrm{L}_{\text {hitung }}=0,203>$ $\mathrm{L}_{\text {tabel }}=0,190$, Karena berdasarkan uji prasyarat salah satu variabel tidak terpenuhi, yaitu variabel kelentukan pergelangan tangan, maka akan dilanjutkan pada pengujian hipotesis menggunakan statsitika nonparametrik dengan uji analisis Rank Sprearman.

C. Pengujan Hipotesis

Pengujian hipotesis pada penelitian ini digunakan analisis korelasi Rank Spearman. Butir-butir atau variabelvariabel tes yang akan diuji korelasinya adalah kelentukan pergelangan tangan dengan ketepatan servis backhand backspin maka hasilnya dapat dilihat pada tabel 3 di bawah ini:

Tabel 3. Hasil Perhitungan Korelasi

$\begin{array}{cccccc}\text { Butir } & \text { Ni } & \text { Kate } & { }^{t}{ }_{\text {hit }} & { }^{t_{-}} \text {tab } & \text { Hasil } \\ \text { Tes } & \text { lai } & \text { gori } & \text { ung } & \text { el } & \\ & r & & & & \end{array}$

\begin{tabular}{llllll}
\hline Kelent & 0, & Seda & 2,3 & 2,1 & Signif \\
ukan & 44 & ng & 37 & 01 & ikan \\
pergela & & & & & \\
ngan & & & & & \\
X $_{1}$ & & & & & \\
dengan & & & & & \\
Ketepa & & & & & \\
tan & & & & & \\
Servis & & & & & \\
Backh & & & & & \\
\hline
\end{tabular}

and

Backsp

in $(\mathrm{Y})$

Untuk menafsirkan nilai korelasi dari ketiga butir tes yang telah dihitung di atas, penulis berpedoman pada interpretasi nilai korelasi yang bersumber dari (Sugiyono, 2011) yang mengemukakan nilai interpertasi dari korelasi koefisien sebagai berikut:

Tabel 4. Interpretasi Nilai Korelasi

\begin{tabular}{cc}
\hline $\begin{array}{c}\text { Interval } \\
\text { Koefisien }\end{array}$ & $\begin{array}{c}\text { Tingkat } \\
\text { Hubungan }\end{array}$ \\
\hline $0,00-0,199$ & Sangat rendah \\
\hline $0,20-0,399$ & Rendah \\
\hline $0,40-0,599$ & Sedang \\
\hline $0,60-0,799$ & Kuat \\
\hline $0,80-1,000$ & Sangat kuat \\
\hline
\end{tabular}

Berdasarkan tabel 4 dan interpretasi nilai korelasi di atas, bahwa kelentukan pergelangan tangan mempunyai kontribusi yang signifikan terhadap ketepatan servis backhand backspin, diperoleh nilai koefisien korelasi sebesar 0,44 dan termasuk kategori sedang. Selanjutnya untuk mencari persentase dukungan dari kelentukan pergelangan tangan dengan ketepatan servis backhand backspin penulis melakukan perhitungan dengan menggunakan rumus determinasi, dan hasilnya adalah sebagai berikut.

Kelentukan pergelangan tangan terhadap ketepatan servis backhand backspin $\quad=0,44^{2} x 100 \%=19,4 \%$ Lainnya $=100 \%-19,4 \%=80,6 \%$

Berdasarkan hasil analisis yang telah dilakukan korelasi spearman (rank) dan korelasi sederhana diperoleh hasil bahwa kelentukan pergelangan tangan memiliki kontribusi yang sedang dengan ketepatan servis backhand backspin pada siswa ekstrakurikuler tenis meja SMK Negeri 2 Tasikmalaya dengan 
koefisien korelasi sebesar 0,44. Hal ini terbukti signifikan secara statistik dengan nilai t sebesar 2,077. Selain itu, kelentukan pergelangan tangan memberikan kontribusi terhadap ketepatan pukulan servis backhand backspin yang cukup besar yaitu sebesar $19,4 \%$ dengan $80,6 \%$ ditentukan oleh variabel lain. Dengan demikian, kesimpulan statistik menyebutkan bahwa kelentukan pergelangan tangan memberikan kontribusi yang cukup besar terhadap servis backhand backspin di ekstrakurikuler tenis meja SMK Negeri 2 Tasikmalaya. Dikarenakan kelentukan pergelangan tangan berfungsi untuk mengarahkan bola sesuai dengan yang server inginkan. Selain itu, kelentukan pergelangan tangan juga sangat membantu pada saat melakukan servis untuk melakukan variasi-variasi pukulan servis.

\section{KESIMPULAN DAN SARAN}

Kesimpulan hasil analisis yang telah dilakukan korelasi spearman (rank) dan korelasi sederhana diperoleh hasil bahwa kelentukan pergelangan tangan terbukti memberikan kontribusi terhadap ketepatan hasil pukulan servis backhand backspin pada permainan tenis meja. Saran dari hasil penelitian ini setelah mendapatkan hasil dari penelitian yang dilakukan penelitian ini dapat dijadikan acuan untuk lebih memperbaiki kemampuan servis backhand backspin, kepada pihak pelatih dan pembina hasil dari penelitian ini dapat dijadikan sebagai evaluasi kemampuan servis backhand backspin tiap anggota ekstrakurikuler, dan juga dapat dijadikan acuan untuk menyusun program latihan kedepannya dan peneliti selanjutnya, agar dapat memperhatikan perihal item variabel lainnya, atau bisa menggunakan bantuan kemajuan teknologi seperti kamera, aplikasi dan lainnya agar penelitian selanjutnya semakin baik dan berkualitas.

\section{DAFTAR PUSTAKA}

Fuchs, M., Liu, R., Lanzoni, I. M., Munivrana, G., Tamaki, S., Yoshida, K., ... Yoshida, K. (2018). Table tennis match analysis : a review Table tennis match analysis : a review. Journal of Sports Sciences, O0(00), 1-10. https://doi.org/10.1080/02640414.2 018.1450073

Harsono. (1988). Coaching. Jakarta: C.V Tambak Kusumah.

Hodges, L. (1996). Tenis Meja Tingkat Pemula. Jakarta: PT. RajaGrafindo Persada.

Indrawan, B., \& Herliana, M. N. (2008). Tenis Meja. Tasikmalaya: Universitas Siliwangi.

Simpson, P. (1981). Tenis Meja. Jakarta: Dian Rakyat Jakarta.

Sugiyono. (2011). Metode penelitian kuantitatif, kualitatif dan $R \& D$. Bandung, Indonesia: Alfabeta.

Tomoliyus. (n.d.). PENGEMBANGAN INSTRUMEN KEMAMPUAN KETEPATAN FORE HAND , BACKHAND DRIVE DALAM, $1-14$. 